\title{
Efficacy of Budesonide/Glycopyrronium/Formoterol Fumarate Metered Dose Inhaler (BGF MDI) Versus Other Inhaled Corticosteroid/Long-Acting Muscarinic Antagonist/Long-Acting $\beta_{2}$-Agonist (ICS/LAMA/LABA) Triple Combinations in COPD: A Systematic Literature Review and Network Meta-analysis
}

\author{
Gary T. Ferguson - Patrick Darken - Shaila Ballal · Mohd Kashif Siddiqui • \\ Barinder Singh · Sumeet Attri · Ulf Holmgren · Enrico de Nigris \\ Received: February 10, 2020 / Published online: April 25, 2020 \\ (c) The Author(s) 2020
}

\section{ABSTRACT \\ Introduction: Triple inhaled corticosteroid/ long-acting muscarinic antagonist/long-acting $\beta_{2^{-}}$ agonist (ICS/LAMA/LABA) combination therapy is recommended for patients with chronic obstruc- tive pulmonary disease (COPD) who experience further exacerbations/symptoms on dual LAMA/ LABA or ICS/LABA therapy. The relative efficacy of budesonide/glycopyrronium/formoterol fuma- rate metered dose inhaler 320/18/9.6 $\mu \mathrm{g}$ (BGF}

Enhanced Digital Features To view enhanced digital features for this article go to https://doi.org/10.6084/ m9.figshare. 12005604 .

Electronic supplementary material The online version of this article (https://doi.org/10.1007/s12325020-01311-3) contains supplementary material, which is available to authorized users.

G. T. Ferguson ( $\square)$

Pulmonary Research Institute of Southeast

Michigan, Farmington Hills, MI, USA

e-mail: garytferguson@msn.com

P. Darken · S. Ballal

AstraZeneca, Morristown, NJ, USA

M. K. Siddiqui · B. Singh · S. Attri

Parexel International, Punjab, India

U. Holmgren

AstraZeneca, Gothenburg, Sweden

E. de Nigris

AstraZeneca, Cambridge, UK
MDI) in COPD was compared with other ICS/ LAMA/LABA fixed-dose and open combination therapies in a network meta-analysis (NMA).

Methods: A systematic literature review was conducted to identify randomized controlled trials of at least 10 -week duration, including at least one fixed-dose or open combination triple therapy arm, in patients with moderate to very severe COPD. Studies were assessed for methodological quality and risk of bias. A threelevel hierarchical Bayesian NMA model was used to determine the exacerbation rate per patient per year as well as the following outcomes at week 24: changes from baseline in predose trough forced expiratory volume in $1 \mathrm{~s}$ $\left(\mathrm{FEV}_{1}\right)$, post-dose peak $\mathrm{FEV}_{1}$, and St. George's Respiratory Questionnaire (SGRQ) total score; proportion of SGRQ responders; and Transition Dyspnea Index focal score. Change from baseline in rescue medication use over weeks 12-24 was also analyzed. Meta-regression and sensitivity analyses were used to assess heterogeneity across studies.

Results: Eighteen studies ( $n=29,232$ patients) contributed to the NMA. ICS/LABA dual combinations were combined as a single treatment group to create a connected network. Across all outcomes, there were no statistically significant differences between BGF MDI and other triple ICS/LAMA/LABA fixed-dose (fluticasone furoate/umeclidinium/vilanterol and beclomethasone dipropionate/glycopyrronium/formoterol 
fumarate) and open combinations with data available within the network. Results from sensitivity analyses and meta-regression were consistent with the base-case scenario.

Conclusion: This NMA suggested that BGF MDI has comparable efficacy to other ICS/LAMA/ LABA fixed-dose and open triple combination therapies in reducing exacerbations and improving lung function and symptoms in patients with moderate to very severe COPD. Further research is warranted as additional evidence regarding triple therapies, especially fixed-dose combinations, becomes available.

Keywords: Chronic obstructive pulmonary disease; Exacerbations; Inhaled corticosteroid; Long-acting muscarinic antagonist; Long-acting $\beta_{2}$-agonist; Lung function; Network metaanalysis; Patient-reported outcomes; Triple therapy

\section{Key Summary Points}

Why carry out this study?

Budesonide/glycopyrronium/formoterol fumarate metered dose inhaler (BGF MDI) is a triple fixed-dose combination therapy for chronic obstructive pulmonary disease (COPD).

Given the relatively recent introduction of fixed-dose triple therapies for COPD, there are no head-to-head randomized controlled trials of their relative efficacy.

We performed a network meta-analysis to compare the relative efficacy of BGF MDI versus other triple therapies (in fixed-dose or open combination) in patients with moderate to very severe COPD.

\section{What was learned from the study?}

On the basis of evidence from 18 studies, BGF MDI was found to have similar efficacy to other fixed-dose and open triple combination therapies in reducing exacerbations and improving lung function and symptoms in patients with moderate to very severe COPD.
The results of this network meta-analysis provide important context for healthcare providers and payers in evaluating the current evidence regarding triple therapies in COPD.

\section{INTRODUCTION}

Chronic obstructive pulmonary disease (COPD) is a progressive disease that causes symptoms including dyspnea, sputum production, and chronic cough, and can be associated with significant comorbidities [1]. COPD is associated with significant morbidity and mortality: it was reported to be the third leading cause of death in 2016, causing an estimated 3.0 million deaths globally [2].

A range of pharmacological treatment options exists for COPD, with the key treatment goals being to reduce symptoms, decrease the risk of exacerbations, and minimize the impact of exacerbations if they occur [1]. Patients with a high symptom burden and a history of exacerbations may be treated with dual bronchodilator therapy [long-acting muscarinic antagonist (LAMA)/long-acting $\beta_{2}$-agonist (LABA)], or for patients who also have elevated eosinophil levels, inhaled corticosteroid (ICS)/ LABA therapy is a recommended initial treatment option [1]. Escalation to ICS/LAMA/LABA triple therapy is recommended for patients who continue to experience symptoms such as breathlessness or difficulty with physical activity while on ICS/LABA treatment, or for patients on LAMA/LABA therapy who continue to have exacerbations and who have eosinophil counts of at least 100 cells/ $\mu \mathrm{L}$ [1]. Notably, the Global Initiative for Chronic Obstructive Lung Disease (GOLD) 2019 report includes, for the first time, a specific treatment pathway for the management of exacerbations, indicating the clinical importance of preventing their occurrence [3].

Combination therapies may be delivered via separate inhalers (in "open" combination) [4-6] or within a single inhaler (in fixed-dose combination) [7-10]. Given the relatively recent 
introduction of fixed-dose triple therapies, there are no head-to-head randomized controlled trials (RCTs) of their relative efficacy in COPD. In the absence of head-to-head data, network meta-analysis (NMA) can be used to compare multiple interventions by combining direct and indirect evidence, adjusting with the use of common comparators [11]. NMA techniques have been applied to compare the efficacy of triple therapy as a class with LAMA/LABA dual therapy or bronchodilator monotherapy [12], and two pairwise meta-analyses have provided comparisons of triple therapies with ICS/LABA $[13,14]$ or LAMA/LABA [14].

Budesonide/glycopyrronium/formoterol fumarate metered dose inhaler (BGF MDI), formulated with co-suspension delivery technology (AEROSPHERE ${ }^{\circledR}$, AstraZeneca), is a triple ICS/LAMA/LABA fixed-dose combination that has recently been approved in Japan and China for the treatment of COPD $[15,16]$. In the phase III KRONOS study, BGF MDI showed benefits in improving lung function and symptoms and reducing COPD exacerbations versus dual LAMA/LABA and ICS/LABA therapies [10]. We performed a systematic literature review (SLR) and NMA to compare the relative clinical efficacy of BGF MDI versus other triple ICS/LAMA/LABA therapies (in fixed-dose or open combination) in patients with moderate to very severe COPD. To our knowledge, this is the first NMA to assess the relative efficacy of triple therapies in COPD. This article is based on previously conducted studies and does not contain any studies with human participants or animals performed by any of the authors.

\section{METHODS}

\section{Systematic Literature Review}

An SLR was conducted to identify evidence on the efficacy of triple ICS/LAMA/LABA fixed-dose or open combination therapies in patients with moderate to very severe COPD, in accordance with the Preferred Reporting Items for Systematic Reviews and Meta-Analyses (PRISMA) guidelines. Searches of Embase ${ }^{\circledR}$, MEDLINE $^{\circledR}$, MEDLINE $^{\circledR}$ In-Process, and the Cochrane
Central Register of Controlled Trials (CENTRAL) were run from database inception to October 2019. Only articles published in English were included. The search strategies are shown in Table S1. Abstracts from the American Thoracic Society, European Respiratory Society, and American College of Chest Physicians conference proceedings were hand-searched from September 2015 to August 2019 to retrieve studies that had not yet been published in fulltext articles or abstracts reporting supplementary results of previously published studies. Additionally, the following trial registries were searched to capture unpublished clinical trials: ClinicalTrials.gov of the US National Institute of Health and the World Health Organization International Clinical Trials Registry Platform.

To be included in the SLR, studies had to meet pre-defined eligibility criteria: the primary criteria were RCTs with a duration of at least 10 weeks, assessing patients of at least 40 years of age with moderate to very severe COPD, published in English, and including at least one treatment arm with fixed-dose or open combination triple therapy (Table 1). Titles and abstracts of publications identified in the search were screened, full-text copies of articles judged to be potentially relevant reviewed, and data for eligible studies extracted using a pre-defined extraction grid, which included details on trial design, inclusion criteria, study population characteristics, interventions, outcome measures, and length of follow-up. Screening, review, and data extraction were conducted by two independent reviewers, with results checked and reconciled by a third independent reviewer. Where a single study was described by more than one publication, the data were compiled into a single entry in the data extraction sheet to avoid duplication, with all publications referenced.

The methodological quality of included studies was assessed using the concise critical appraisal checklists provided by the National Institute for Health and Care Excellence (NICE) in the Single Technology Appraisal user guide [17]. The risk of bias was assessed with respect to the method of randomization and allocation concealment, comparability of baseline characteristics, blinding, the balance of withdrawals 
Table 1 Population, interventions, comparators, outcomes, and study design criteria for inclusion in the network meta-analysis

\begin{tabular}{|c|c|}
\hline Population & $\begin{array}{l}\text { Adult patients }(\geq 40 \text { years of age) of any } \\
\text { gender or race with moderate to very } \\
\text { severe COPD (predicted } \mathrm{FEV}_{1} \leq 80 \% \text { ) }\end{array}$ \\
\hline Interventions & $\begin{array}{l}\text { Triple therapies (ICS + LAMA + LABA, } \\
\text { both fixed-dose and open combinations) }\end{array}$ \\
\hline \multirow[t]{4}{*}{ Comparators } & Any included intervention \\
\hline & $\begin{array}{l}\text { Dual therapies (ICS + LABA or } \\
\text { LAMA + LABA both fixed-dose and } \\
\text { open combinations) }\end{array}$ \\
\hline & Monotherapies (ICS/LAMA/LABA) \\
\hline & Placebo \\
\hline \multirow[t]{6}{*}{ Outcomes } & Efficacy outcomes \\
\hline & $\begin{array}{l}\text { Exacerbations (severe only, moderate to } \\
\text { severe) }\end{array}$ \\
\hline & Lung function (peak $\mathrm{FEV}_{1}$, trough $\mathrm{FEV}_{1}$ ) \\
\hline & SGRQ total score and SGRQ responders \\
\hline & TDI focal score \\
\hline & Use of rescue medication \\
\hline Study designs & $\begin{array}{l}\text { Randomized controlled trials of } \\
\geq 10 \text { weeks duration }\end{array}$ \\
\hline
\end{tabular}

COPD chronic obstructive pulmonary disease, $F E V_{1}$ forced expiratory volume in $1 \mathrm{~s}$, ICS inhaled corticosteroid, $L A B A$ long-acting $\beta_{2}$-agonist, $L A M A$ longacting muscarinic antagonist, $S G R Q$ St. George's Respiratory Questionnaire, TDI Transition Dyspnea Index

between groups, outcomes reporting, and statistical analysis.

\section{Network Meta-analysis}

The NMA followed the recommended best practice of the NICE Decision Support Unit for evidence synthesis [18, 19]. Relevant results were combined using a three-level hierarchical Bayesian NMA model, which assumes exchangeability between treatments within the same class, i.e., that all studies measure the same underlying relative treatment effects $[20,21]$. This model accounted for the exchangeability between interventions of the same class (i.e., LAMA monotherapy, ICS/LABA dual combinations, ICS/LAMA/LABA triple combinations) by assuming that underlying treatment effects within each class followed a normal distribution with class-specific mean and variance. Thus, estimates of treatment effects and their uncertainty are affected by both the evidence propagated through the network, as well as the borrowed strength between treatments in the same class. The synthesis was conducted from a Bayesian perspective, using WinBUGS (a Markov chain Monte Carlo simulation-based software for Bayesian inference) version 1.4.3. The NMA WinBUGS code, developed initially by Dias et al. [22], was adapted to incorporate a three-level hierarchical class-effect model [20, 21, 23]. Results were generated using both random- and fixed-effects models and compared for goodness-of-fit to the data, calculated as the overall mean residual deviance. The goodness of fit was assessed using the Deviance Information Criterion (DIC); the model with the lowest DIC was considered the model with the best fit to the data. If DIC and residual deviance were comparable between models, a random-effects model was preferred as it takes into account additional heterogeneity in the network, but a fixed-effects model was used when the number of contributing studies was five or fewer. Results are presented as posterior median effect estimates with 95\% credible limits: rate ratios for counts outcomes modeled with a Poisson model (exacerbations), mean differences for continuous outcomes [forced expiratory volume in $1 \mathrm{~s}\left(\mathrm{FEV}_{1}\right)$, St. George's Respiratory Questionnaire (SGRQ), Transition Dyspnea Index (TDI), and rescue medication use], and odds ratios for binary outcomes (SGRQ responders). No type I error control was performed, as is common with other studies of this nature using a Bayesian framework [24]. For continuous outcomes, results were considered non-significant if the credible interval (CrI) contained the null value; for Poisson/binomial outcomes, results were considered non-significant if the CrI contained 1. Inconsistencies between direct and indirect estimates were 
checked, where appropriate, for outcomes where both direct and indirect data were available for the comparison of interest (further details are provided in the Supplementary methods).

A separate NMA was performed for each of the outcomes of interest. Exacerbations were assessed as the mean rate of exacerbations per patient per year (moderate/severe and severe exacerbations, analyzed as relative ratios for BGF MDI vs comparators). Lung function endpoints were the change from baseline in trough $\mathrm{FEV}_{1}$ and the change from baseline in peak $\mathrm{FEV}_{1}$, both at week 24 . The following patientreported outcomes were assessed: change from baseline in SGRQ total score at 24 weeks, proportion of SGRQ responders (patients who experienced an improvement that met or exceeded the minimum clinically important difference of at least 4 units [25]) at 24 weeks, TDI focal score at 24 weeks, and change from baseline in rescue medication use over 12-24 weeks. Analysis of TDI responders could not be performed because of variation between studies in the reporting of this outcome.

Studies reporting data between 22 and 26 weeks were considered for inclusion in the 24-week analyses. For the exacerbation outcomes, there was no limit applied on the basis of maximum trial duration, as the treatments were compared using rates (events per patientyear). Networks were presented graphically with a "node" representing each intervention and an "edge" representing the comparison between them. Each node was weighted according to the number of patients receiving that intervention, and each edge was weighted according to the number of studies included for the comparison.

Several sensitivity analyses were undertaken. The base-case scenario included only doubleblind studies; therefore, a sensitivity analysis was performed, including both double-blind and open-label studies in one network. A sensitivity analysis was also performed, including only studies in which the majority of the patient population was symptomatic (defined as a COPD assessment test (CAT) score of at least 10 or a modified Medical Research Council (mMRC) dyspnea scale score of at least 2).
Additionally, a meta-regression analysis was conducted for the efficacy outcomes with at least 10 studies to account for differences in selected baseline patient characteristics that could be acting as the key effect modifiers.

\section{RESULTS}

\section{Study Selection}

The SLR process is shown in Fig. 1. Initial database searches identified 15,542 publications, with 2742 removed owing to duplication across databases searched. Initial screening of the 12,800 remaining records (based on titles and abstracts) reduced eligible publications to 1589 , which were subject to full-text review. A further 32 citations were identified from conference proceedings and bibliographies of identified publications, including a clinical study report for an RCT with BGF MDI. Following full-text review, a total of 23 studies from 165 publications met the inclusion criteria of the SLR. Five studies did not report any efficacy outcome of interest at specified time points, thus leaving 18 studies [4-10, 26-34] that contributed to the NMA (Table 2; Table S2).

\section{Study Characteristics}

All 18 of the studies included were multicenter, the majority were phase III, two were open-label, and the remainder were double-blind (Table 2). All studies included in the NMA were adjudged to pose a low risk of bias with respect to randomization and allocation concealment, baseline characteristics, the balance of withdrawals between groups, and statistical analysis (Table S3). High risk of bias in blinding was associated with two open-label studies $[4,5]$, and one study was considered to have a high risk of bias with respect to outcome selection and reporting [31].

\section{Analysis Assumptions}

When all treatments reported in the included studies were considered, there was no 


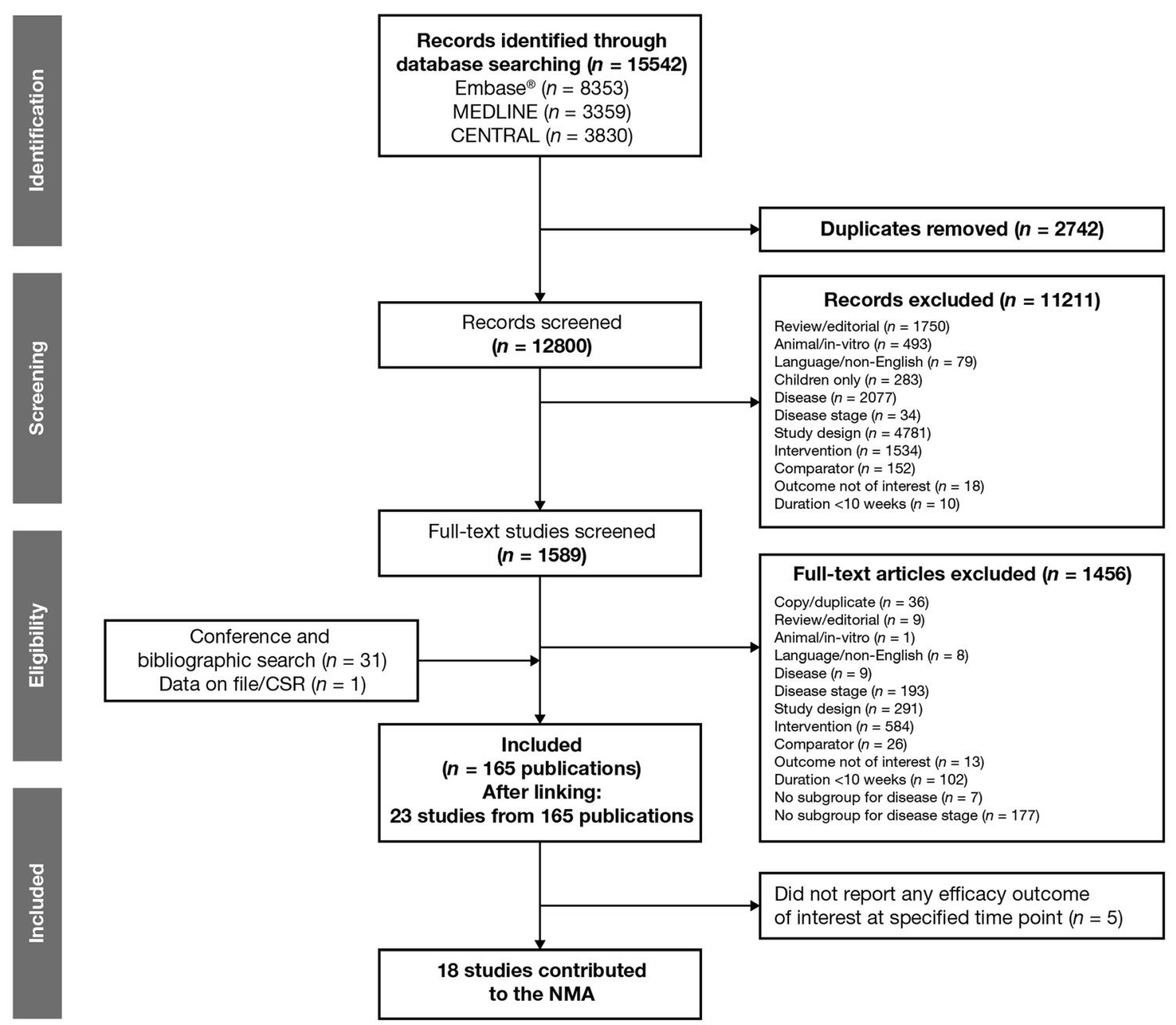

Fig. 1 PRISMA flowchart. CSR clinical study report, $N M A$ network meta-analysis

interlinked network allowing comparison of BGF MDI with other triple therapies in the base-case analysis, which included only doubleblind studies ( $n=16$; Fig. $2 \mathrm{a})$. Therefore, to create an interlinked network, all ICS/LABA dual combinations were considered as a single treatment group (Fig. 2b). The networks of evidence for each outcome varied according to the endpoints available from each study (Figs. S1-S3).

\section{Patient Baseline Clinical Characteristics}

A total of 29,232 evaluable patients contributed to the NMA. Patient characteristics were generally similar in terms of age, gender, body mass index, and smoking status, but differences were noted in disease duration, race, symptom burden, COPD severity, and exacerbation history (Table 3). These potential differences in key effect modifiers could not be adjusted in a metaregression model because of the limited number of studies contributing to the NMA, except for moderate/severe exacerbations and severe exacerbations. For these outcomes, meta-regression was feasible for prior exacerbation history, smoking status, BMI, and disease severity, as classified by GOLD (III or IV). Thirteen of the 18 studies included enrolled only symptomatic patients, while the remainder did not describe any inclusion criteria regarding symptom burden. 


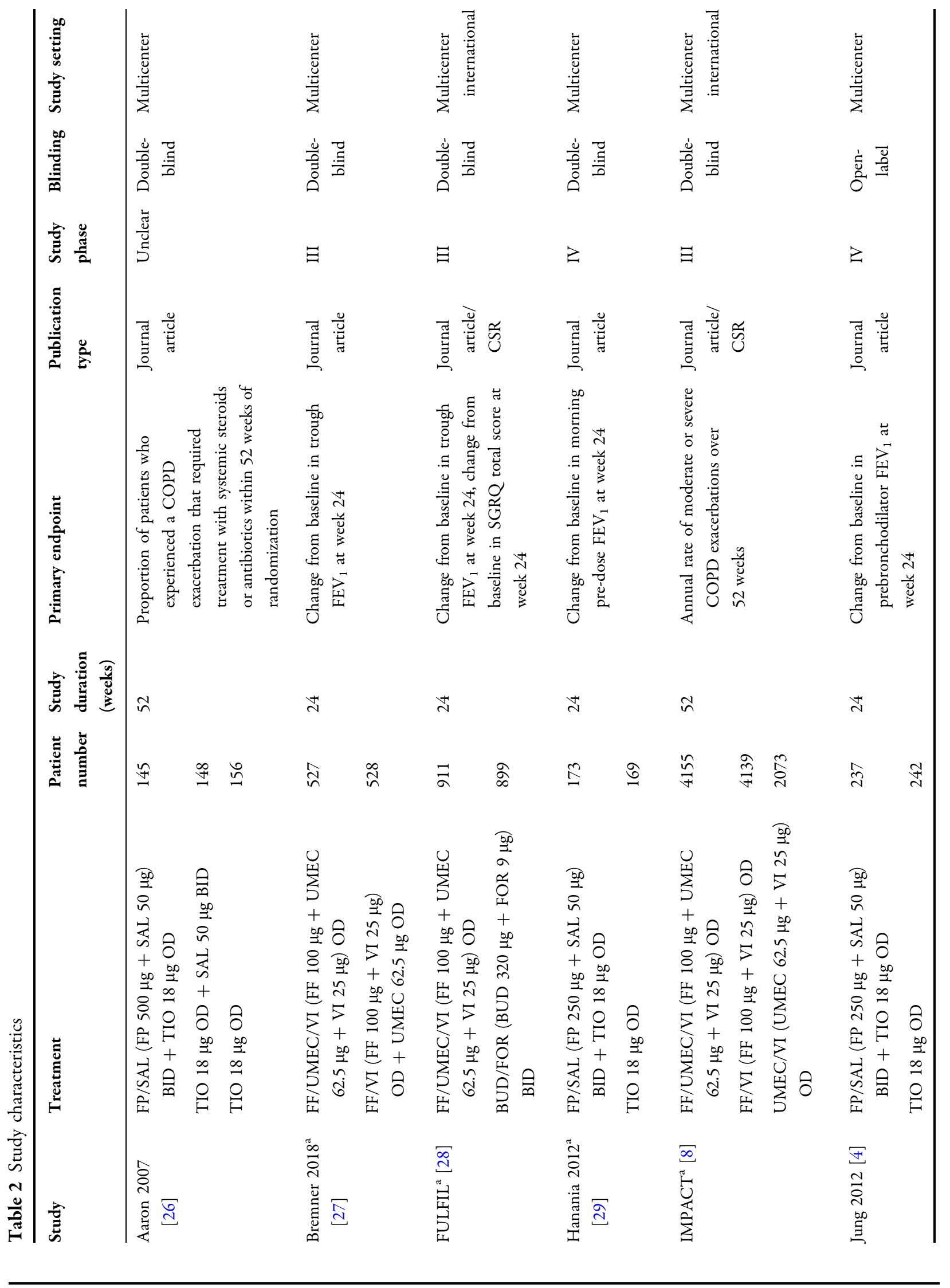




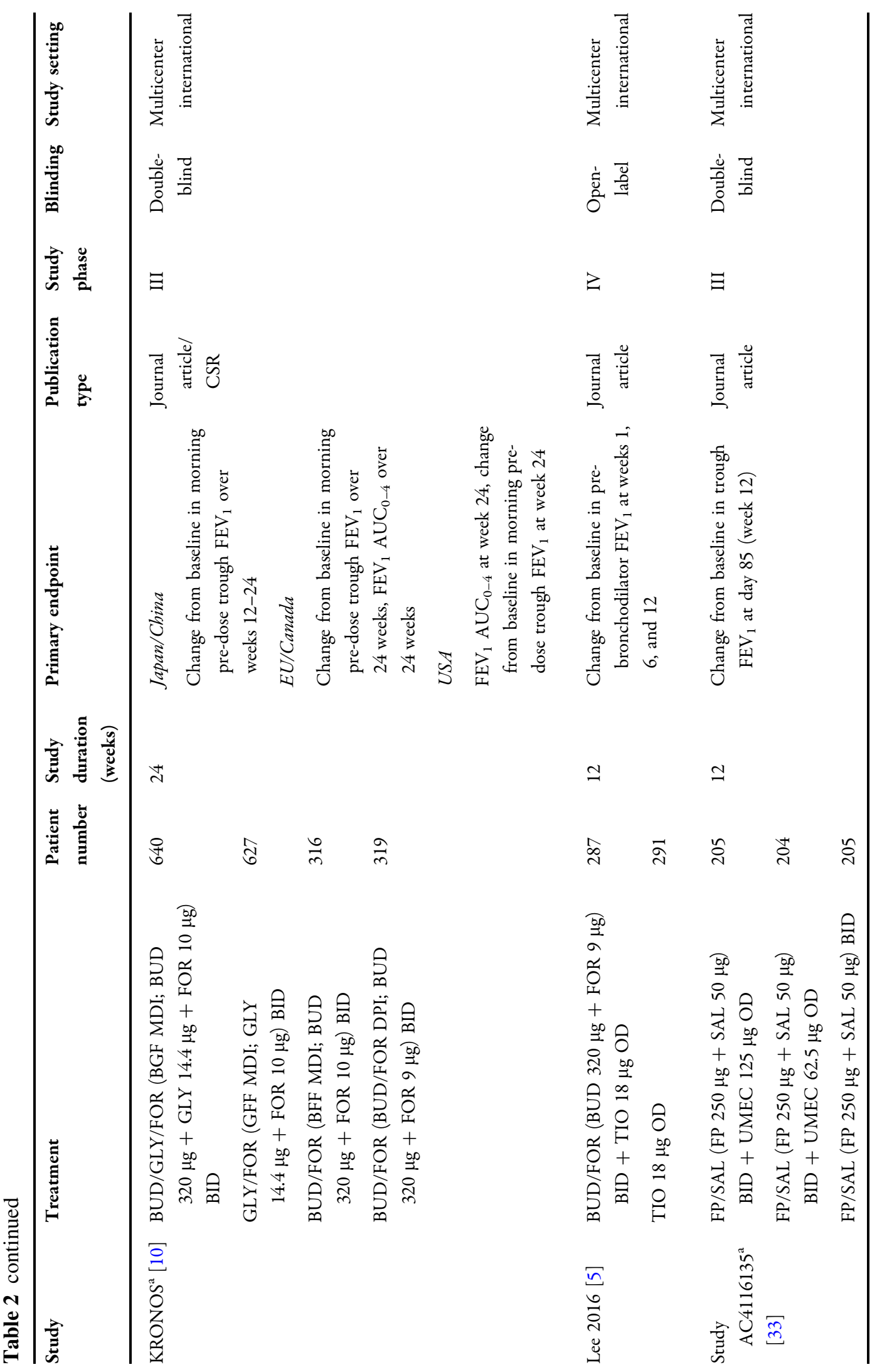




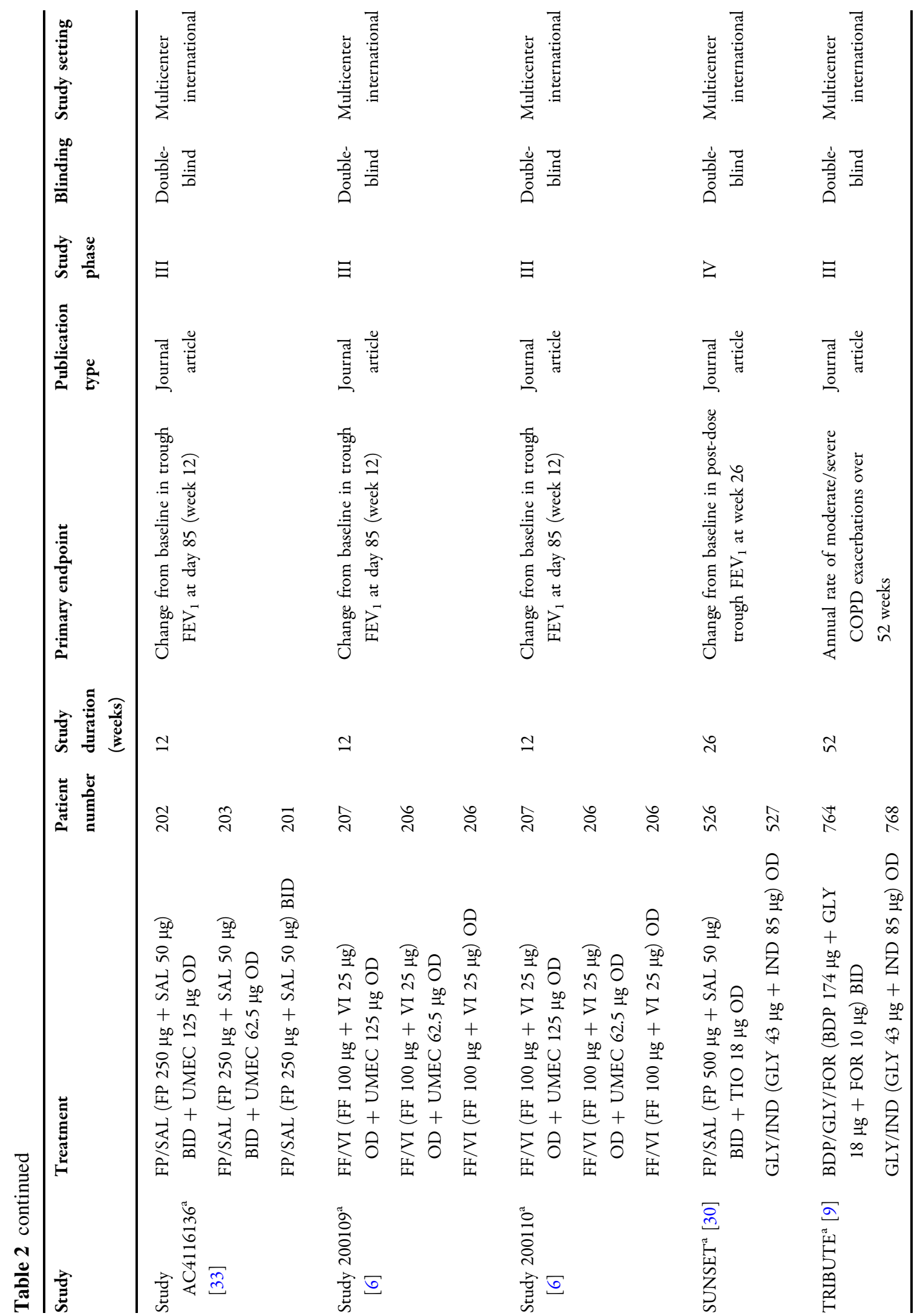




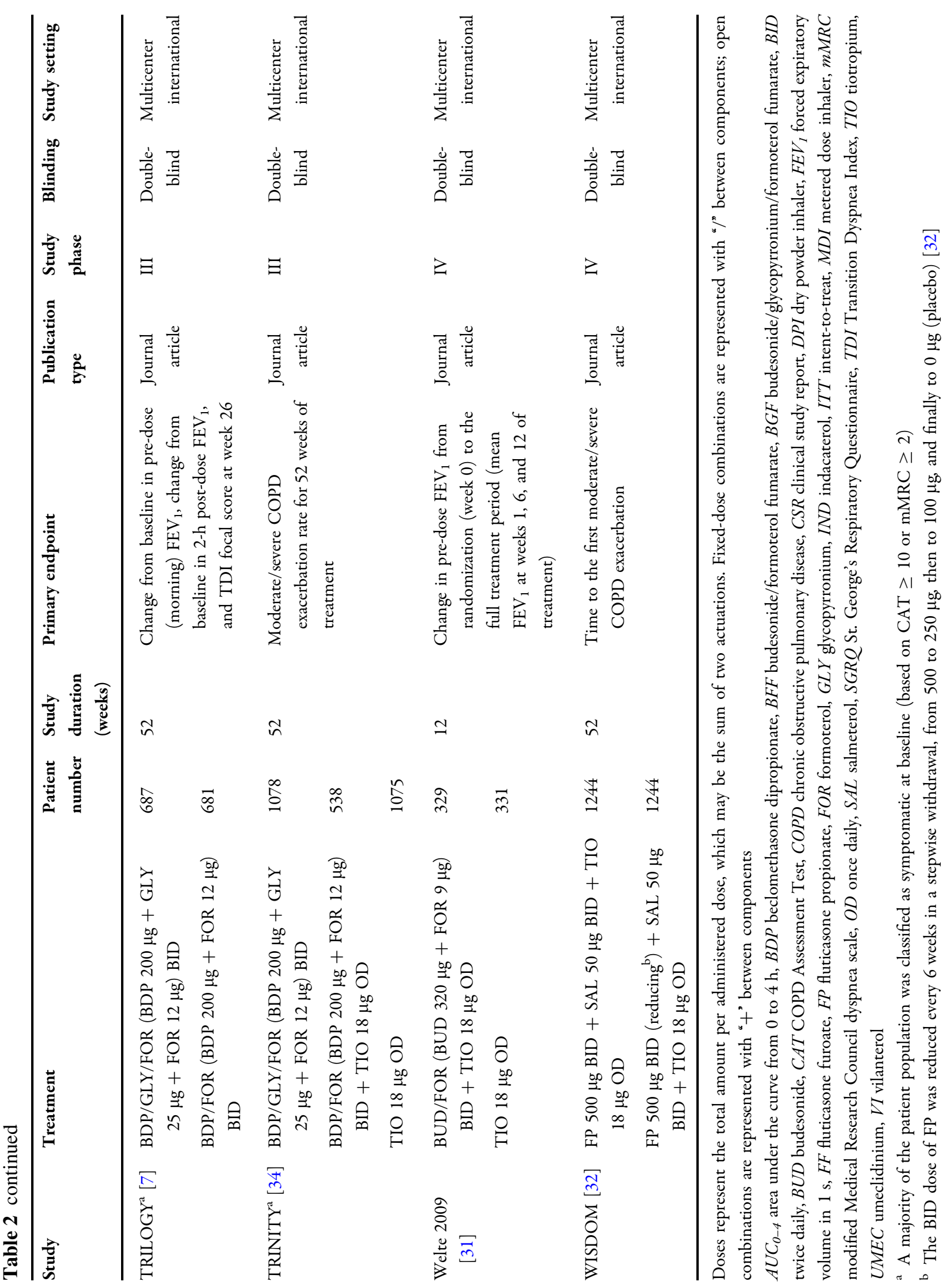



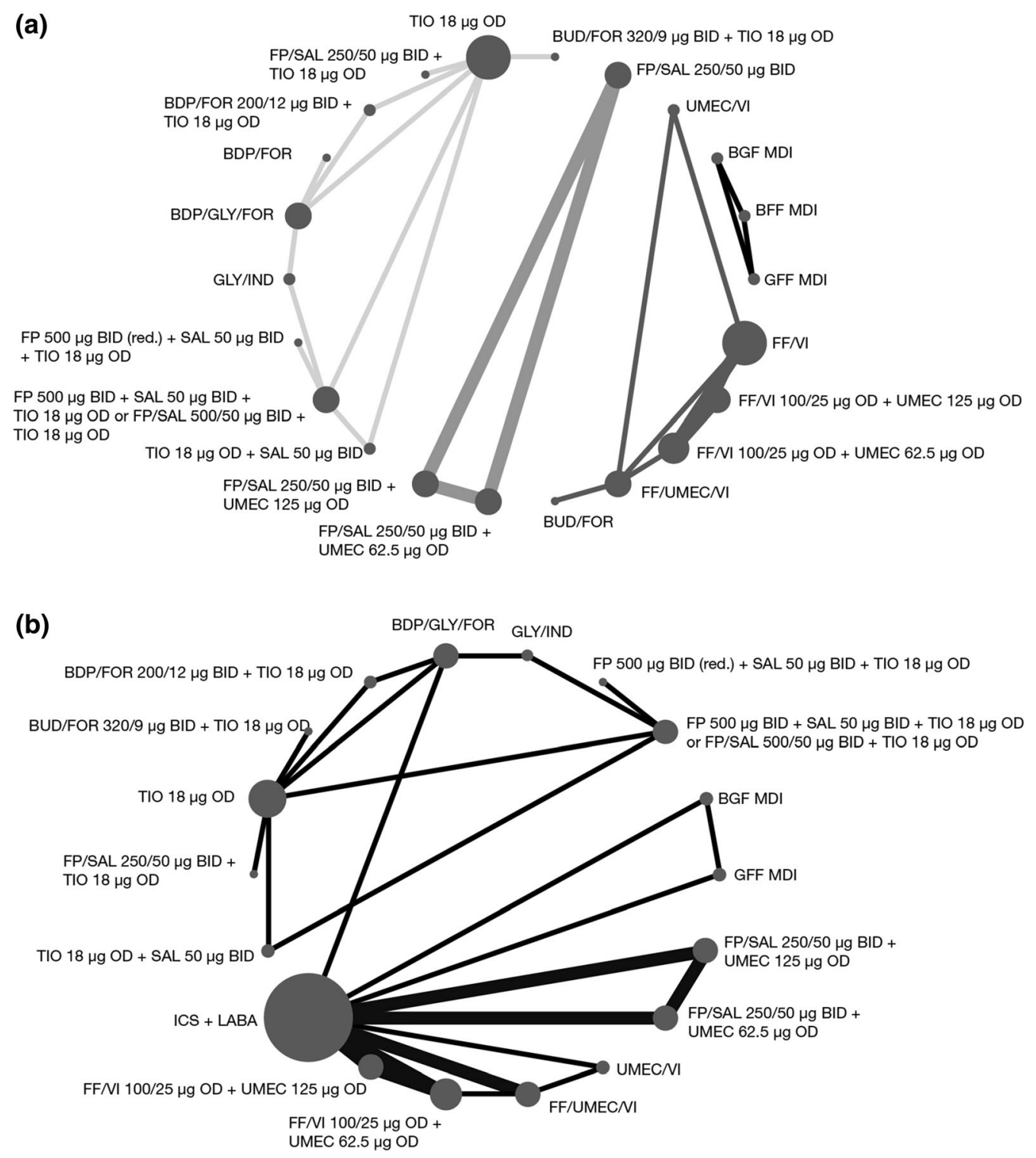

Fig. 2 Networks using treatments as reported (a), and using all ICS/LABA treatments as a single treatment group (b). Fixed-dose combinations are represented with "/" between components; open combinations are represented with " + " between components. BDP beclomethasone dipropionate, $B F F$ budesonide/formoterol fumarate, $B G F$ budesonide/glycopyrronium/formoterol fumarate, $B I D$ twice daily, $B U D$ budesonide, $F F$ fluticasone furoate,

\section{Efficacy}

For each outcome, findings are presented for all comparisons with data available within the network.
FOR formoterol, FP fluticasone propionate, GFF glycopyrronium/formoterol fumarate, GLY glycopyrronium, ICS inhaled corticosteroid, IND indacaterol, $L A B A$ longacting $\beta_{2}$-agonist, $M D I$ metered dose inhaler, $O D$ once daily, red. reducing, $S A L$ salmeterol, TIO tiotropium, UMEC umeclidinium, $V I$ vilanterol

\section{Exacerbations}

Moderate/severe and severe exacerbations were reported in 15 and 12 studies, respectively, with one study excluded from the severe exacerbations analysis as no events were reported 


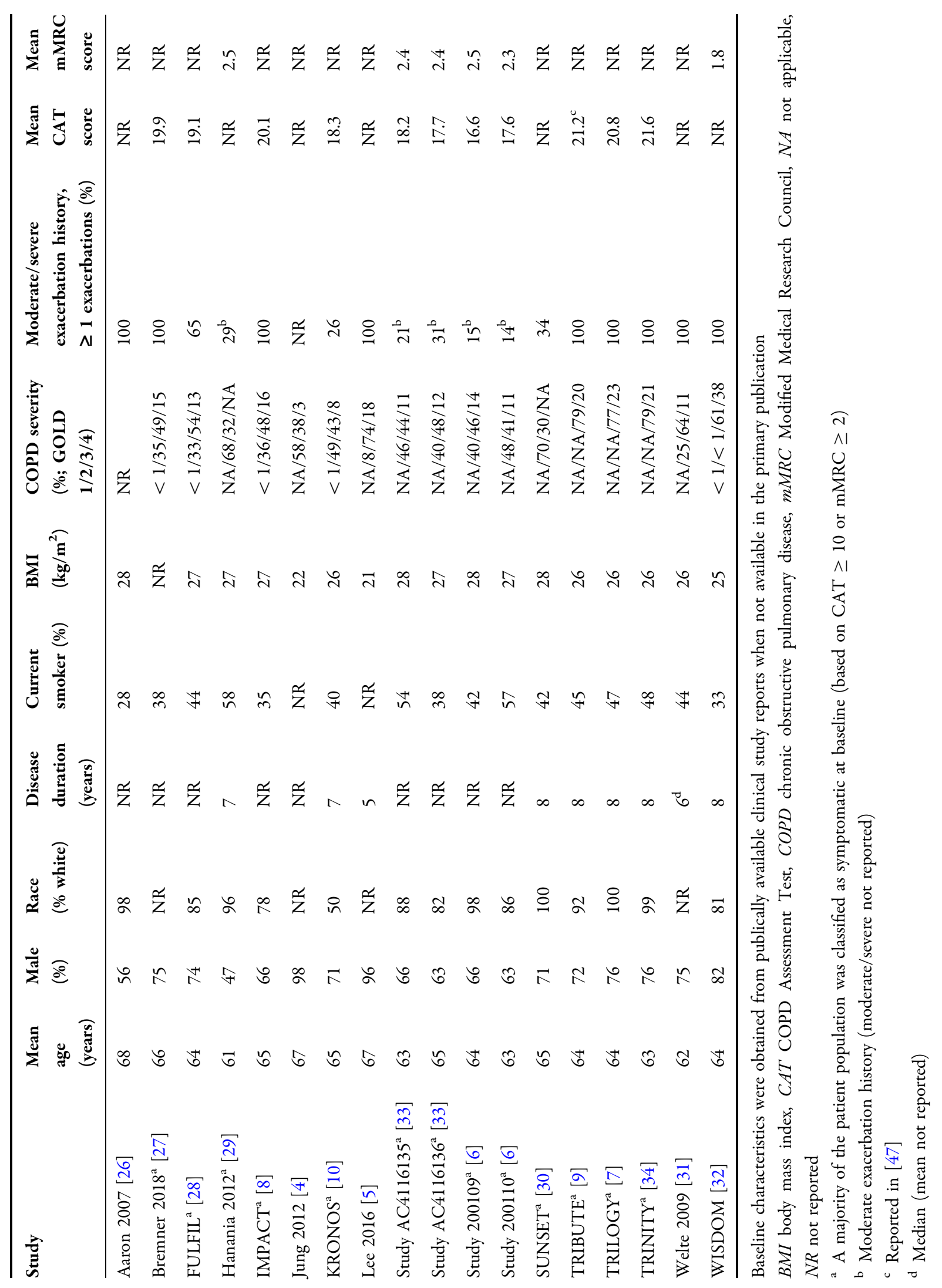


(a)

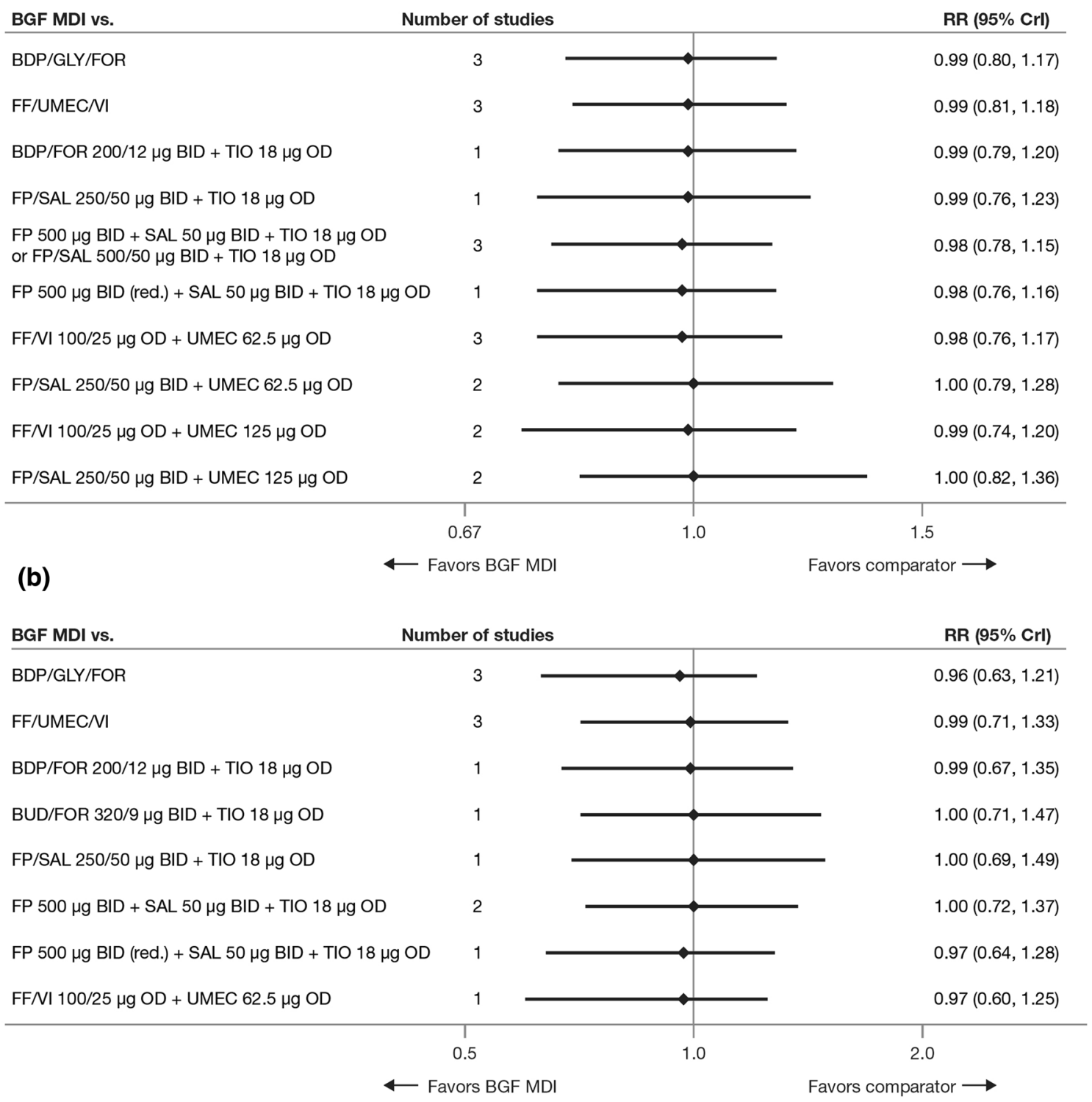

Fig. 3 Rate ratio of (a) moderate/severe exacerbations and (b) severe exacerbations. Fixed-dose combinations are represented with "/" between components; open combinations are represented with " + " between components. $B D P$ beclomethasone dipropionate, $B G F$ budesonide/ glycopyrronium/formoterol fumarate, BUD budesonide,

(networks shown in Fig. S1). The definitions of moderate and severe exacerbations were broadly similar among the included studies. BGF MDI 320/18/9.6 $\mu \mathrm{g}$ twice daily (BID) showed comparable reductions in moderate/severe exacerbations to two other triple ICS/
$C r I$ credible interval, $F F$ fluticasone furoate, FOR formoterol, FP fluticasone propionate, GLY glycopyrronium, $M D I$ metered dose inhaler, red. reducing, $R R$ rate ratio, $S A L$ salmeterol, TIO tiotropium, UMEC umeclidinium, $V I$ vilanterol

LAMA/LABA fixed-dose combinations [beclomethasone dipropionate/glycopyrronium/formoterol fumarate (BDP/GLY/FOR 100/6/12.5 BID) and fluticasone furoate/umeclidinium/vilanterol (FF/UMEC/VI 100/62.5/25 $\mu \mathrm{g}$ once daily (OD))] and eight open triple 
(a)

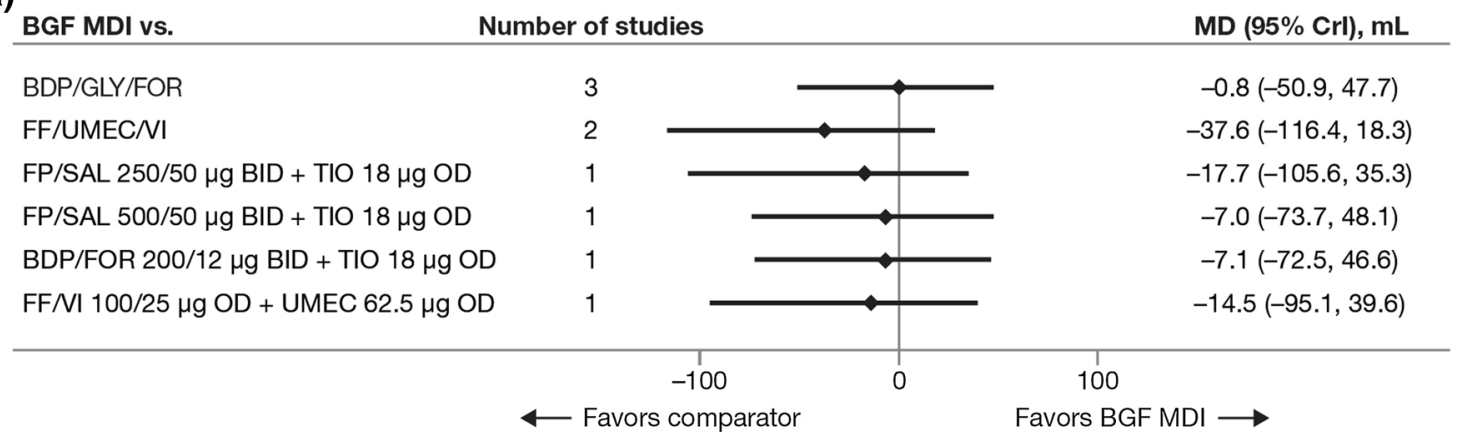

(b)

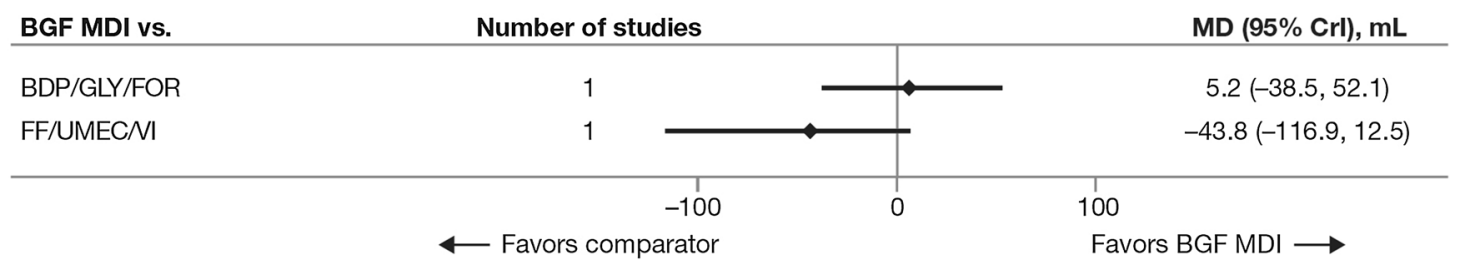

Fig. 4 Lung function endpoints at 24 weeks. Change from baseline in (a) trough $\mathrm{FEV}_{1}$ and (b) peak $\mathrm{FEV}_{1}$. Fixed-dose combinations are represented with "/ between components; open combinations are represented with " + ” between components. BDP beclomethasone dipropionate, $B G F$ budesonide/glycopyrronium/formoterol fumarate,

combinations (Fig. 3a). BGF MDI also showed a comparable reduction in severe exacerbations to FF/UMEC/VI, BDP/GLY/FOR, and six open triple combinations (Fig. 3b).

\section{Lung Function}

Changes from baseline in trough and peak $\mathrm{FEV}_{1}$ at 24 weeks were reported in nine and four studies, respectively (networks shown in Fig. S2). At 24 weeks, BGF MDI showed comparable effect on trough $\mathrm{FEV}_{1}$ to $\mathrm{BDP} / \mathrm{GLY} / \mathrm{FOR}, \mathrm{FF} / \mathrm{UMEC} / \mathrm{VI}$, and four open triple combinations [fluticasone propionate + tiotropium + salmeterol

(FP/SAL $250 / 50 \mu \mathrm{g}$ BID + TIO $18 \mu \mathrm{g}$ OD and FP/SAL $500 / 50 \mu \mathrm{g}$ BID + TIO $18 \mu \mathrm{g}$ OD), beclomethasone dipropionate + tiotropium + formoterol (BDP/ FOR 200/12 $\mu \mathrm{g}$ BID + TIO $18 \mu \mathrm{g}$ OD), and fluticasone furoate + umeclidinium + vilanterol $(\mathrm{FF} /$ VI 100/25 $\mu \mathrm{g}$ OD + UMEC $62.5 \mu \mathrm{g}$ OD)] (Fig. 4a).

At 24 weeks, BGF MDI showed comparable improvement in peak $\mathrm{FEV}_{1}$ to $\mathrm{BDP} / \mathrm{GLY} / \mathrm{FOR}$ and FF/UMEC/VI (Fig. 4b).
$C r I$ credible interval, $F E V_{1}$ forced expiratory volume in $1 \mathrm{~s}, F F$ fluticasone furoate, FOR formoterol, FP fluticasone propionate, $G L Y$ glycopyrronium, $M D$ mean difference, $M D I$ metered dose inhaler, $S A L$ salmeterol, TIO tiotropium, UMEC umeclidinium, VI vilanterol

\section{Quality of Life and Symptoms}

Changes from baseline in SGRQ total score at 24 weeks were reported in eight studies (network shown in Fig. S3a). At 24 weeks, BGF MDI showed comparable improvement in SGRQ total score to BDP/GLY/FOR, FF/UMEC/VI, and three open triple combinations (BDP/FOR 200/12 $\mu \mathrm{g} \quad \mathrm{BID}+\mathrm{TIO} \quad 18 \mu \mathrm{g} \quad$ OD, FP/SAL $500 / 50 \mu \mathrm{g}$ BID + TIO $18 \mu \mathrm{g}$ OD, and FF/VI 100/25 $\mu$ g OD + UMEC 62.5 $\mu$ g OD) (Fig. 5a).

Changes at week 24 in TDI focal score were reported in five studies (network shown in Fig. S3b). At 24 weeks, BGF MDI showed comparable improvements in TDI focal score to BDP/ GLY/FOR, FF/UMEC/VI, and an open triple combination (FF/VI 100/25 $\mu \mathrm{g}$ OD + UMEC $62.5 \mu \mathrm{g}$ OD) (Fig. 5b).

Rescue medication use over 12-24 weeks was reported in six studies (network shown in Fig. S3c). Over 12-24 weeks, BGF MDI showed a comparable reduction in mean puffs per day of rescue medication versus $\mathrm{BDP} / \mathrm{GLY} / \mathrm{FOR}$, $\mathrm{FF} / \mathrm{UMEC} / \mathrm{VI}$, and an open triple combination (BDP/FOR $200 / 12 \mu \mathrm{g} \quad$ BID + TIO $18 \mu \mathrm{g} \quad$ OD) (Fig. 5c). 
(a)

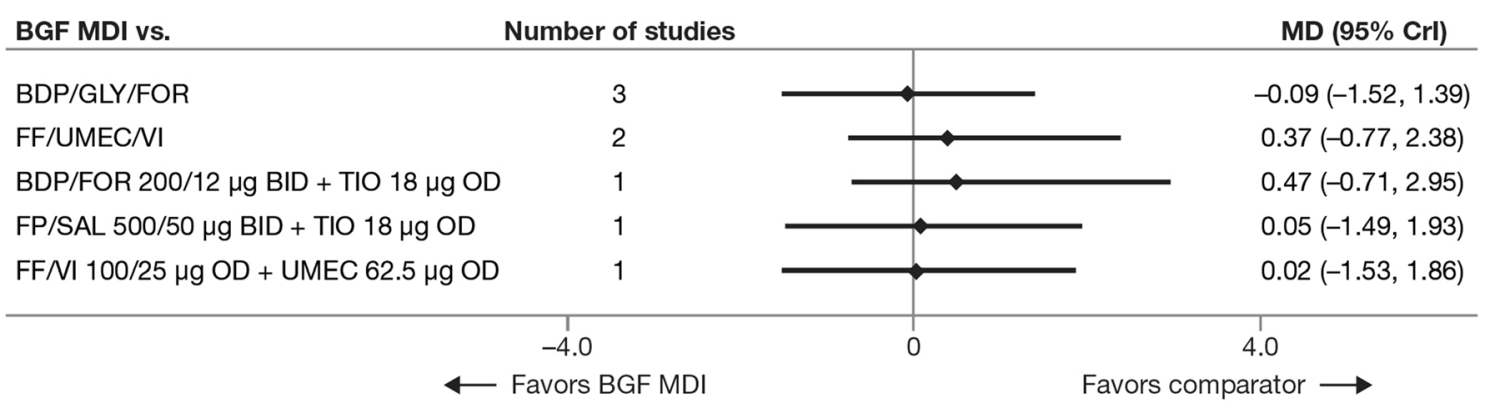

(b)

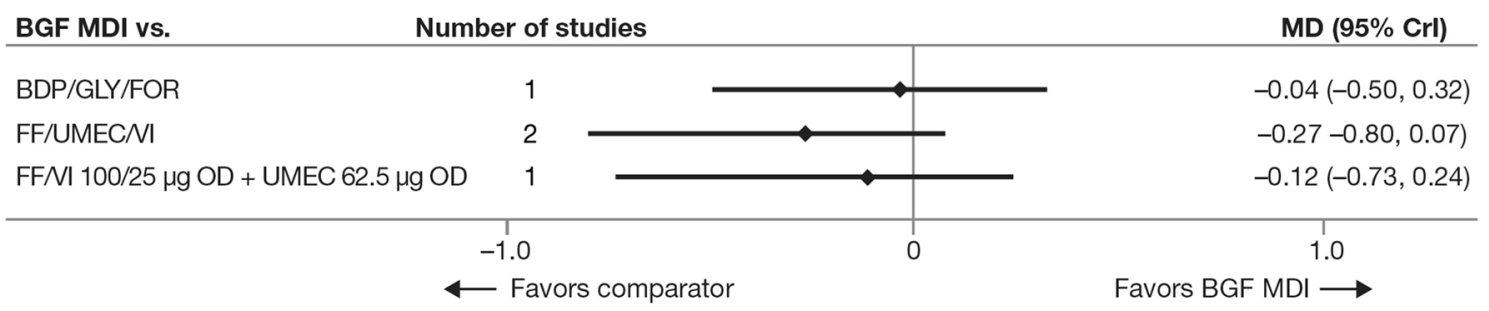

(c)

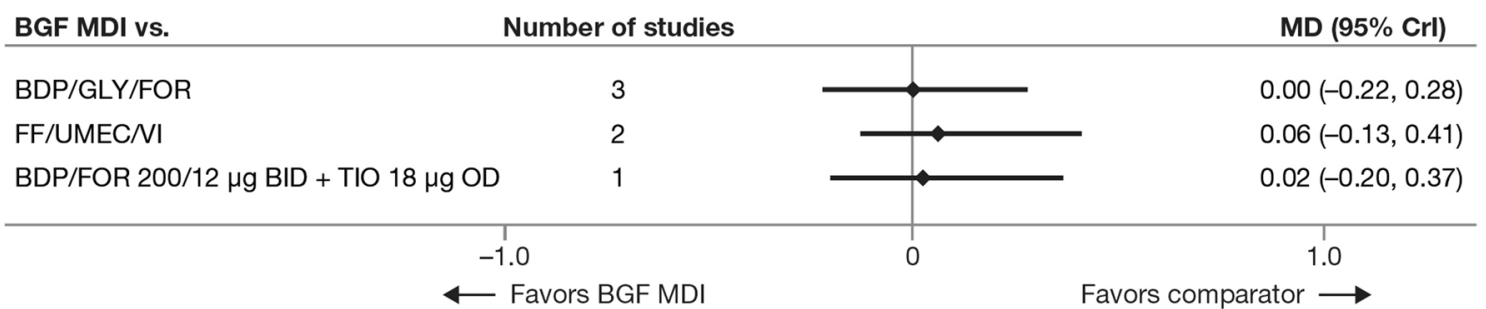

Fig. 5 Health-related quality of life and symptom endpoints. (a) Change from baseline in SGRQ total score at 24 weeks, (b) TDI focal score at 24 weeks, and (c) change from baseline in daily rescue medication use over 12-24 weeks. Fixed-dose combinations are represented with "/" between components; open combinations are represented with " + " between components. $B D P$ beclomethasone dipropionate, $B G F$ budesonide/

\section{Inconsistency Testing}

Where feasible, assessments of inconsistency were performed. For the majority of outcomes, no direct comparisons were available, so statistical inconsistency checks between direct and indirect comparisons were not possible. For moderate/severe exacerbations, the results of the consistency assessment indicated no inconsistency between direct and indirect estimates for all comparisons, i.e., the 95\% glycopyrronium/formoterol fumarate, $C r I$ credible interval, $F F$ fluticasone furoate, FOR formoterol, FP fluticasone propionate, GLY glycopyrronium, $M D$ mean difference, $M D I$ metered dose inhaler, $S A L$ salmeterol, $S G R Q$ St. George's Respiratory Questionnaire, TDI Transition Dyspnea Index, TIO tiotropium, UMEC umeclidinium, $V I$ vilanterol

confidence intervals for the inconsistency estimates contained 0 .

\section{Sensitivity Analyses and Meta-Regression}

Meta-regression and sensitivity analyses were conducted to examine the impact of heterogeneity across the studies included in the NMA. Analyses of lung function, symptom, and exacerbation outcomes, including open-label studies produced results in line with the base- 
case model, which only included double-blind studies (Table S4). The studies included in the base-case were conducted entirely in symptomatic patients, with the exception of one study that assessed the open combination budesonide (BUD)/FOR + TIO [31] and two studies that assessed open combinations of FP, SAL, and TIO [26, 32]. Sensitivity analyses excluding these studies produced findings in line with the base-case model for all comparisons (Table S4). There was no statistically significant association between the covariates assessed in the meta-regression and treatment effects on severe exacerbations, which indicated that no linear relationship could be demonstrated between these covariates and treatment effect size (Table S5). For moderate/severe exacerbations, there were no significant associations with BMI, disease severity, or prior exacerbation history, but there was a significant negative association with current smokers at baseline (Table S5). For both endpoints, results from the meta-regression were broadly similar to the base-case NMA. None of the covariateadjusted models offered notable improvement in between-study variability compared to unadjusted models. The meta-regression results should be interpreted with caution, as the analyses were based on aggregate data, to allow for accurate modeling of the effect of covariates on the treatment effect.

\section{DISCUSSION}

This SLR and NMA compared the efficacy of BGF MDI with other triple ICS/LAMA/LABA fixed-dose or open combinations in the treatment of mostly symptomatic patients with moderate to very severe COPD. NMAs are increasingly recognized as an essential form of evidence in developing healthcare guidelines, especially in areas of clinical practice where direct head-to-head trials are lacking $[35,36]$. To date, three triple fixed-dose combinations have been developed and, as yet, no head-tohead trials of these therapies have been performed. Therefore, this NMA provides important context for healthcare providers and payers in evaluating the current evidence regarding triple therapies in COPD. Our findings suggested that the efficacy of BGF MDI is comparable with all other fixed-dose (BDP/GLY/FOR and FF/UMEC/VI) and open triple ICS/LAMA/ LABA combination therapies with respect to reducing exacerbation rates and improving lung function, quality of life, and symptoms.

Exacerbations of COPD are associated with significant morbidity and mortality, and reducing the risk of future exacerbations is a key goal of treatment $[1,37]$. Reductions in moderate/severe exacerbations and severe exacerbations with BGF MDI were comparable to BDP/ GLY/FOR, FF/UMEC/VI, and all open triple combinations evaluated. The effect of BGF MDI in reducing exacerbations in a patient population with high exacerbation risk has been investigated in the phase III ETHOS study, which reported topline results for more than 8500 patients in August 2019 [38]. This study will provide a more considerable body of evidence to evaluate the efficacy and safety profiles of two different doses of BGF MDI (160/18/ $9.6 \mu \mathrm{g}$ and 320/18/9.6 $\mu \mathrm{g}$ ) and will allow for more precise estimates of the comparison between triple therapies with regard to exacerbation rates [39].

When the relative efficacy of different treatments is comparable, other factors should be considered in choosing the right inhaler for individual patients. COPD medications are available in a variety of device types, including MDIs, dry powder inhalers, smooth mist inhalers, and nebulizers. Each device has advantages and disadvantages; the optimal inhaler for each patient depends on their preferences (e.g., device familiarity, ease of use, size, cost), disease characteristics (e.g., inspiratory flow), and abilities (e.g., hand-breath coordination, grip strength, and dexterity) [1, 40-42]. While this NMA suggests comparable efficacy with fixeddose and open triple combinations in RCTs conducted in highly controlled settings, realworld studies have reported higher medication adherence and persistence in patients with COPD using fewer inhalers [43-45]. A 12-month retrospective cohort study found higher adherence to triple therapy in patients with COPD who were using two inhalers versus three inhalers [43]. Similarly, a retrospective 
observational study of patients with COPD who were receiving LAMA, LABA, and/or ICS therapy in single or multiple inhalers showed that the proportion of adherent patients was higher for single-inhaler users versus multiple inhaler users [44]. Persistence was also higher for single versus multiple inhalers, with a significantly higher risk of discontinuation in users of multiple inhalers [44]. The use of a dual combination inhaler versus two individual inhalers has also been associated with a lower risk of respiratory-related hospitalization and reduced healthcare costs [45]. Together, these studies suggest that in real-world use, fixed-dose combination triple therapies may result in better patient outcomes than open triple therapy with multiple inhalers despite comparable efficacy, owing to improved adherence and persistence. However, to our knowledge, specific comparisons of adherence and persistence for fixeddose triple therapies versus open triple therapies in real-world use have not yet been reported.

Several limitations of the NMA methodology should be acknowledged. Different ICS/LABAs were grouped under a single treatment class to resolve the disconnected network. While this approach has been used in previous meta-analyses [12, 13], it means that intra-class differences among ICS/LABAs would not have been captured within the analyses. However, intraclass differences in dual therapies were beyond the objective of this NMA.

NMAs and traditional pairwise meta-analyses depend upon an assumption of similarity between the included studies, including in their patient populations, study design, and outcome measures [11]. While the studies included in this NMA were broadly similar, there were some differences in study design and patient populations across studies, including disease severity and exacerbation history. While statistical inconsistency checks were not possible for most outcomes because of the lack of direct comparisons available within the networks, for the one outcome with direct comparisons available (moderate/severe exacerbations), no inconsistency was identified. Potential sources of clinical heterogeneity were explored in sensitivity analyses and meta-regression where possible, and the results were consistent with the base- case scenario. While some outcomes could not be assessed with meta-regression because of a smaller number of studies reporting data, the study populations were broadly similar across studies (moderate to very severe COPD), and the majority of studies included in the NMA were considered to have a low risk of bias. Further research is warranted as additional evidence regarding triple therapies, especially fixed-dose combinations, becomes available.

In conclusion, this NMA of 18 studies suggests that BGF MDI has similar efficacy to other ICS/LAMA/LABA fixed-dose and open combination therapies in reducing exacerbation rates and improving lung function and symptoms in patients with moderate to very severe COPD.

\section{ACKNOWLEDGEMENTS}

The authors thank Pragya Shukla (formerly of Parexel International) and Akanksha Sharma (Parexel International) for their assistance with the analyses.

Funding. This systematic literature review and network meta-analysis was conducted by Parexel International Ltd and funded by AstraZeneca. No authors received financial compensation in relation to authorship on this manuscript. AstraZeneca funded the journal's article Rapid Service Fee and Open Access fee.

Medical Writing Assistance. Medical writing support, under the direction of the authors, was provided by Carole Evans, Ph.D., on behalf of CMC Connect, McCann Health Medical Communications, funded by AstraZeneca, Gaithersburg, USA in accordance with Good Publication Practice (GPP3) guidelines [46].

Authorship. All named authors meet the International Committee of Medical Journal Editors (ICMJE) criteria for authorship for this article, take responsibility for the integrity of the work as a whole, and have given their approval for this version to be published. 
Authorship Contributions. Patrick Darken, Shaila Ballal, Ulf Holmgren, and Enrico de Nigris made substantial contributions to the conception and design of the study. Mohd Kashif Siddiqui, Barinder Singh, and Sumeet Attri performed the meta-analysis. All authors contributed to the interpretation of the data, critically revised the manuscript, approved the final version to be submitted, and agree to be accountable for all aspects of the work in ensuring that questions related to the accuracy or integrity of any part of the work are appropriately investigated and resolved.

Disclosures. Gary T Ferguson reports grants, personal fees, and non-financial support from AstraZeneca during the conduct of the study; grants, personal fees and non-financial support from AstraZeneca, Boehringer Ingelheim, Novartis, and Sunovion; grants and personal fees from Theravance; and personal fees from Circassia, GlaxoSmithKline, Innoviva, Mylan, and Verona, outside of the submitted work. Patrick Darken, Ulf Holmgren, and Enrico de Nigris are employees of AstraZeneca and hold stock in the company. Shaila Ballal is an employee of AstraZeneca. Mohd Kashif Siddiqui, Barinder Singh, and Sumeet Attri are employees of Parexel International, the organization that received funding from AstraZeneca to perform the systematic literature review and network meta-analysis.

Compliance with Ethics Guidelines. This article is based on previously conducted studies and does not contain any studies with human participants or animals performed by any of the authors.

Data Availability. The datasets generated during and/or analyzed during the current study are available from the corresponding author on reasonable request.

Open Access. This article is licensed under a Creative Commons Attribution-NonCommercial 4.0 International License, which permits any non-commercial use, sharing, adaptation, distribution and reproduction in any medium or format, as long as you give appropriate credit to the original author(s) and the source, provide a link to the Creative Commons licence, and indicate if changes were made. The images or other third party material in this article are included in the article's Creative Commons licence, unless indicated otherwise in a credit line to the material. If material is not included in the article's Creative Commons licence and your intended use is not permitted by statutory regulation or exceeds the permitted use, you will need to obtain permission directly from the copyright holder. To view a copy of this licence, visit http://creativecommons.org/licenses/by$\mathrm{nc} / 4.0 /$.

\section{REFERENCES}

1. Global Initiative for Chronic Obstructive Lung Disease. 2020 Report: Global Strategy for the Diagnosis, Management and Prevention of COPD; 2020. https://goldcopd.org. Accessed Nov 5, 2019.

2. World Health Organization. Global Health Estimates 2016: deaths by cause, age, sex, by country and by region 2000-2016; 2018. https://www.who. int/healthinfo/global_burden_disease/estimates/ en/. Accessed Apr 11, 2019.

3. Global Initiative for Chronic Obstructive Lung Disease. 2019 Report: global strategy for the diagnosis, management and prevention of COPD; 2019. https://goldcopd.org. Accessed Oct 28, 2019.

4. Jung KS, Park HY, Park SY, et al. Comparison of tiotropium plus fluticasone propionate/salmeterol with tiotropium in COPD: a randomized controlled study. Respir Med. 2012;106:382-9.

5. Lee SD, Xie CM, Yunus F, et al. Efficacy and tolerability of budesonide/formoterol added to tiotropium compared with tiotropium alone in patients with severe or very severe COPD: a randomized, multicentre study in East Asia. Respirology. 2016;21:119-27.

6. Siler TM, Kerwin E, Sousa AR, Donald A, Ali R, Church A. Efficacy and safety of umeclidinium added to fluticasone furoate/vilanterol in chronic obstructive pulmonary disease: results of two randomized studies. Respir Med. 2015;109:1155-63.

7. Singh D, Papi A, Corradi $\mathrm{M}$, et al. Single inhaler triple therapy versus inhaled corticosteroid plus long-acting $\beta_{2}$-agonist therapy for chronic obstructive pulmonary disease (TRILOGY): a double-blind, 
parallel group, randomised controlled trial. Lancet. 2016;388:963-73.

8. Lipson DA, Barnhart F, Brealey N, et al. Once-daily single-inhaler triple versus dual therapy in patients with COPD. N Engl J Med. 2018;378:1671-80.

9. Papi A, Vestbo J, Fabbri L, et al. Extrafine inhaled triple therapy versus dual bronchodilator therapy in chronic obstructive pulmonary disease (TRIBUTE): a double-blind, parallel group, randomised controlled trial. Lancet. 2018;391:1076-84.

10. Ferguson GT, Rabe KF, Martinez FJ, et al. Triple therapy with budesonide/glycopyrrolate/formoterol fumarate with co-suspension delivery technology versus dual therapies in chronic obstructive pulmonary disease (KRONOS): a double-blind, parallel-group, multicentre, phase 3 randomised controlled trial. Lancet Respir Med. 2018;6:747-58.

11. Tonin FS, Rotta I, Mendes AM, Pontarolo R. Network meta-analysis: a technique to gather evidence from direct and indirect comparisons. Pharm Pract (Granada). 2017;15:943.

12. Cazzola M, Rogliani P, Calzetta L, Matera MG. Triple therapy versus single and dual long-acting bronchodilator therapy in COPD: a systematic review and meta-analysis. Eur Respir J. 2018;52: 1801586.

13. Calzetta L, Cazzola M, Matera MG, Rogliani P. Adding a LAMA to ICS/LABA therapy: a metaanalysis of triple combination therapy in COPD. Chest. 2019;155:758-70.

14. Zayed Y, Barbarawi M, Kheiri B, et al. Triple versus dual inhaler therapy in moderate-to-severe COPD: a systematic review and meta-analysis of randomized controlled trials. Clin Respir J. 2019;13:413-28.

15. AstraZeneca. Breztri Aerosphere (PT010) approved in Japan for patients with chronic obstructive pulmonary disease; 2019. https://www.astrazeneca. com/media-centre/press-releases/2019/breztriaerosphere-pt010-approved-in-japan-for-patientswith-chronic-obstructive-pulmonary-disease19062019.html. Accessed July 2, 2019.

16. AstraZeneca. AstraZeneca's triple-combination therapy approved in China for patients with COPD; 2019. https://www.astrazeneca.com/media-centre/ press-releases/2019/astrazenecas-triple-combina tion-therapy-approved-in-china-for-patients-withcopd-23122019.html. Accessed Dec 23, 2019.

17. National Institute for Health and Care Excellence. Single technology appraisal: User guide for company evidence submission template. last updated 2015. https://www.nice.org.uk/process/pmg24/ chapter/5-clinical-effectiveness\#quality-assessment -of-the-relevant-randomised-controlled-trials. Accessed June 4, 2019.

18. Dias S, Welton NJ, Sutton AJ, Ades AE. NICE DSU Technical Support Document 2: a generalised linear modelling framework for pairwise and network meta-analysis of randomised controlled trials. 2011, last updated September 2016. http://nicedsu.org. uk/wp-content/uploads/2017/05/TSD2-Generalmeta-analysis-corrected-2Sep2016v2.pdf. Accessed Jan 23, 2019.

19. Dias S, Sutton AJ, Welton NJ, Ades AE. NICE DSU Technical Support Document 3: Heterogeneity: subgroups, meta-regression, bias and bias-adjustment; 2011, last updated April 2012. http:// nicedsu.org.uk/wp-content/uploads/2016/03/TSD 3-Heterogeneity.final-report.08.05.12.pdf. Accessed Jan 23, 2019.

20. Owen RK, Tincello DG, Abrams KR. Network metaanalysis: development of a three-level hierarchical modeling approach incorporating dose-related constraints. Value Health. 2015;18:116-26.

21. Phillippo DM, Dias S, Ades AE, Didelez V, Welton NJ. Sensitivity of treatment recommendations to bias in network meta-analysis. J R Stat Soc Ser A Stat Soc. 2018;181:843-67.

22. Dias S, Welton NJ, Caldwell DM, Ades AE. Checking consistency in mixed treatment comparison metaanalysis. Stat Med. 2010;29:932-44.

23. National Institute for Health and Care Excellence. Depression in adults: treatment and management. Appendix N1: network meta-analysis-detailed methods and results; 2018. https://www.nice.org. uk/guidance/gid-cgwave0725/documents/ addendum-appendix-19. Accessed 4 Apr 2020.

24. Schlueter M, Gonzalez-Rojas N, Baldwin M, Groenke L, Voss F, Reason T. Comparative efficacy of fixed-dose combinations of long-acting muscarinic antagonists and long-acting $\beta 2$-agonists: a systematic review and network meta-analysis. Ther Adv Respir Dis. 2016;10:89-104.

25. Jones PW. St. George's Respiratory Questionnaire: MCID. COPD. 2005;2:75-9.

26. Aaron SD, Vandemheen KL, Fergusson D, et al. Tiotropium in combination with placebo, salmeterol, or fluticasone-salmeterol for treatment of chronic obstructive pulmonary disease: a randomized trial. Ann Intern Med. 2007;146:545-55.

27. Bremner PR, Birk R, Brealey N, Ismaila AS, Zhu CQ, Lipson DA. Single-inhaler fluticasone furoate/ umeclidinium/vilanterol versus fluticasone furoate/ vilanterol plus umeclidinium using two inhalers for 
chronic obstructive pulmonary disease: a randomized non-inferiority study. Respir Res. 2018;19:19.

28. Lipson DA, Barnacle H, Birk R, et al. FULFIL trial: once-daily triple therapy for patients with chronic obstructive pulmonary disease. Am J Respir Crit Care Med. 2017;196:438-46.

29. Hanania NA, Crater GD, Morris AN, Emmett AH, O'Dell DM, Niewoehner DE. Benefits of adding fluticasone propionate/salmeterol to tiotropium in moderate to severe COPD. Respir Med. 2012;106: 91-101.

30. Chapman KR, Hurst JR, Frent SM, et al. Long-term triple therapy de-escalation to indacaterol/glycopyrronium in patients with chronic obstructive pulmonary disease (SUNSET): a randomized, double-blind, triple-dummy clinical trial. Am J Respir Crit Care Med. 2018;198:329-39.

31. Welte T, Miravitlles M, Hernandez P, et al. Efficacy and tolerability of budesonide/formoterol added to tiotropium in patients with chronic obstructive pulmonary disease. Am J Respir Crit Care Med. 2009;180:741-50.

32. Magnussen H, Disse B, Rodriguez-Roisin R, et al. Withdrawal of inhaled glucocorticoids and exacerbations of COPD. N Engl J Med. 2014;371:1285-94.

33. Siler TM, Kerwin E, Singletary K, Brooks J, Church A. Efficacy and safety of umeclidinium added to fluticasone propionate/salmeterol in patients with COPD: results of two randomized, double-blind studies. COPD. 2016;13:1-10.

34. Vestbo J, Papi A, Corradi M, et al. Single inhaler extrafine triple therapy versus long-acting muscarinic antagonist therapy for chronic obstructive pulmonary disease (TRINITY): a double-blind, parallel group, randomised controlled trial. Lancet. 2017;389:1919-29.

35. Kanters S, Ford N, Druyts E, Thorlund K, Mills EJ, Bansback N. Use of network meta-analysis in clinical guidelines. Bull World Health Organ. 2016;94: 782-4.

36. Faltinsen EG, Storebø OJ, Jakobsen JC, Boesen K, Lange T, Gluud C. Network meta-analysis: the highest level of medical evidence? BMJ Evid Based Med. 2018;23:56-9.

37. Epstein D, Barak-Corren Y, Isenberg Y, Berger G. Clinical decision support system: a pragmatic tool to improve acute exacerbation of COPD discharge recommendations. COPD. 2019;16:18-24.
38. AstraZeneca. Breztri Aerosphere Phase III ETHOS trial met its primary endpoint in chronic obstructive pulmonary disease; 2019. https://www. astrazeneca.com/media-centre/press-releases/2019/ breztri-aerosphere-phase-iii-ethos-trial-met-itsprimary-endpoint-in-chronic-obstructive-pulmon ary-disease-28082019.html Accessed Jan 23, 2020.

39. Rabe KF, Martinez FJ, Ferguson GT, et al. A phase III study of triple therapy with budesonide/glycopyrrolate/formoterol fumarate metered dose inhaler $320 / 18 / 9.6 \mu \mathrm{g}$ and 160/18/9.6 $\mu \mathrm{g}$ using co-suspension delivery technology in moderate-to-very severe COPD: the ETHOS study protocol. Respir Med. 2019;158:59-66.

40. Scichilone N, Benfante A, Bocchino M, et al. Which factors affect the choice of the inhaler in chronic obstructive respiratory diseases? Pulm Pharmacol Ther. 2015;31:63-7.

41. Molimard M, Colthorpe P. Inhaler devices for chronic obstructive pulmonary disease: insights from patients and healthcare practitioners. J Aerosol Med Pulmon Drug Deliv. 2015;28:219-28.

42. Rogliani P, Calzetta L, Coppola A, et al. Optimizing drug delivery in COPD: the role of inhaler devices. Respir Med. 2017;124:6-14.

43. Bogart M, Stanford RH, Laliberté F, Germain G, Wu JW, Duh MS. Medication adherence and persistence in chronic obstructive pulmonary disease patients receiving triple therapy in a USA commercially insured population. Int J Chron Obstruct Pulmon Dis. $2019 ; 14: 343-52$.

44. Yu AP, Guérin A, Ponce de Leon D, et al. Therapy persistence and adherence in patients with chronic obstructive pulmonary disease: multiple versus single long-acting maintenance inhalers. J Med Econ. 2011;14:486-96.

45. Chrischilles E, Gilden D, Kubisiak J, Rubenstein L, Shah H. Delivery of ipratropium and albuterol combination therapy for chronic obstructive pulmonary disease: effectiveness of a two-in-one inhaler versus separate inhalers. Am J Manag Care. 2002;8:902-11.

46. Battisti WP, Wager E, Baltzer L, et al. Good publication practice for communicating company-sponsored medical research: GPP3. Ann Intern Med. 2015;163:461-4.

47. Singh D, Fabbri LM, Vezzoli S, Petruzzelli S, Papi A. Extrafine triple therapy delays COPD clinically important deterioration vs ICS/LABA, LAMA, or LABA/LAMA. Int J Chron Obstruct Pulmon Dis. 2019;14:531-46. 